\title{
PDCD4 functions as a suppressor for pT2a and pT2b stage gastric cancer
}

\author{
PENG-TAO GUO ${ }^{1}$, DONG YANG ${ }^{2}, \mathrm{ZHE} \mathrm{SUN}^{1}$ and HUI-MIAN XU ${ }^{1}$ \\ Departments of ${ }^{1}$ Surgical Oncology and ${ }^{2}$ General Surgery, First Affiliated Hospital, \\ China Medical University, Shenyang, Liaoning 110001, P.R. China
}

Received October 25, 2012; Accepted November 27, 2012

DOI: $10.3892 /$ or.2013.2232

\begin{abstract}
Gastric cancer is one of the leading causes of cancer-related mortality worldwide. Loss of programmed cell death 4 (PDCD4) expression has been detected in gastric cancer. However, the effects of PDCD4 on pT2 stage gastric cancer remain unclear. The aim of this study was to identify the relationship between PDCD4 expression and clinicopathological features of patients with pT2 stage gastric cancer. In the present study, 122 pT2 stage gastric cancer specimens were subclassified as pT2a and pT2b stage. The levels of PDCD4 mRNA and protein in gastric cancer tissues were lower compared to that in normal tissues as detected by real-time PCR and western blot analysis, respectively. In addition, both PDCD4 mRNA and protein in pT2b stage gastric cancer were lower when compared to that in pT2a stage gastric cancer. Finally, we used immunohistochemistry to determine the protein expression and analyzed the relationship between PDCD4 expression and the clinicopathological features of pT2 stage gastric cancer patients. Cumulative survival rate of patients with PDCD4 expression was significantly higher compared to the patients without PDCD4 expression. PDCD4 expression in gastric cancer can be employed to indicate a favorable prognosis for the disease outcome.
\end{abstract}

\section{Introduction}

Gastric cancer is one of the leading causes of cancer-related mortality worldwide. A total of 989,600 new stomach cancer cases and 738,000 deaths are estimated to have occurred in 2008 , accounting for $8 \%$ of the total cases and $10 \%$ of total deaths (1). Depth of invasion and lymph node status or optimization of pT (primary tumor) and $\mathrm{pN}$ (regional lymph nodes) category are important prognostic factors for gastric

Correspondence to: Dr Hui-Mian Xu, Department of Surgical Oncology, First Affiliated Hospital, China Medical University, Shenyang, Liaoning 110001, P.R. China

E-mail: cmu_directorhm@163.com

Key words: PDCD4, gastric cancer, apoptosis, cell cycle, survival analysis cancer (2-4). In 2002, the 6th edition of the International Union Against Cancer (UICC)/American Joint Committee on Cancer (AJCC) further divided pT2 gastric adenocarcinomas into type pT2a [invasion of the muscularis propria (MP)] and type pT2b [invasion of the subserosa (SS)] (5). Moreover, previous studies have clearly demonstrated that multiple genetic alterations are responsible for the development and progression of gastric cancer similar to other human cancers $(6,7)$.

Programmed cell death 4 (PDCD4) has been demonstrated to inhibit tumor promoter-induced neoplastic transformation in a murine JB6 cell model system (8). The human PDCD4 gene was found to be localized on chromosome 10q24 (9). Its encoding product is a $64-\mathrm{kDa}$ protein involved in the apoptotic machinery, which suppresses cell transformation, tumorigenesis and invasion (10-12). PDCD4 is expressed in many normal tissues, such as normal mammary gland and normal human lung tissue $(13,14)$. Its levels were found to be markedly decreased in primary patient tumor samples from lung cancer (14), breast carcinoma (10), colon cancer (15) and hepatocellular carcinoma (16).

Previous research has demonstrated the relationship between gastric cancer and PDCD4 (17). However, to the best of our knowledge no studies have shown whether PDCD4 is associated with pT2a and pT2b stage gastric cancers. In the present study, gastric cancer specimens were classified as stages pT2a and pT2b and the levels of PDCD4 mRNA and protein were evaluated. Finally, we used immunohistochemistry to determine the expression of PDCD4 protein and analyzed the relationship between PDCD4 expression and the clinicopathological features of the patients with pT2 stage gastric cancer.

\section{Patients and methods}

Subjects. Specimens from 122 patients with pT2 stage gastric cancer were obtained from the Department of Surgical Oncology, First Affiliated Hospital, China Medical University (Shenyang, China) from January 2001 to December 2010 and classified into pT2a and pT2b stages according to the UICC/AJCC pT staging system. None of the patients underwent radiotherapy or chemotherapy prior to surgery. This study was in compliance with the Helsinki Declaration. All patients provided written informed consent for participation, and the procedure was approved by our university ethics committee. 
Semi-quantitative real-time PCR. Total tissue RNA was isolated using TRIzol reagent (Invitrogen, Carlsbad, CA, USA) and was reverse transcribed using SuperScript II reverse transcriptase (Invitrogen) according to the manufacturer's protocol. Real-time PCR was performed using primers specific for $P D C D 4$ and $G A P D H$. The following primer sets were used: $P D C D 4$ sense, 5'-GTATGATGTGGAGGAGGTGGAT-3' and antisense, 5'-CCCTCCAATGCTAAGGATACTG-3'; GAPDH sense, 5'-GAAGGTGAAGGTCGGAGT-3' and antisense, 5'-CATGGGTGGaAtCATATTGGAA-3'. Real-time PCR analysis was performed using the ABI PRISM 7500 sequence detection system (Applied Biosystems, Foster City, CA, USA) using the SYBR-Green PCR Master mixture (Takara, Dalian, China). The PCR conditions were as follows: 1 cycle at $95^{\circ} \mathrm{C}$ for $10 \mathrm{~min}$ followed by 40 cycles at $95^{\circ} \mathrm{C}$ for $15 \mathrm{sec}$ and at $60^{\circ} \mathrm{C}$ for $1 \mathrm{~min}$. Relative quantitation was calculated by the $\Delta \Delta \mathrm{Ct}$ method. Each reaction was repeated independently three times in triplicate.

Western blot analysis. Tissues were lysed in lysis buffer (20 mM Tris-HCl, $150 \mathrm{mM} \mathrm{NaCl}, 2 \mathrm{mM}$ EDTA, $1 \%$ Triton X-100) containing a protease inhibitor cocktail (Sigma-Aldrich, St. Louis, MO, USA). Protein amounts from the cell extract were quantified using the BCA protein assay kit. Equivalent amounts of protein $(60 \mu \mathrm{g})$ were separated using 12\% SDS-PAGE and transferred to PVDF membranes (Millipore Corp., Billerica, MA, USA). Western blot analysis was performed using primary antibodies: PDCD4 (Cell Signaling Technology, Beverly, MA, USA) and $\beta$-actin (Santa Cruz Biotechnology, Santa Cruz, CA, USA). Binding of each specific antibody was detected with horseradish peroxidase (HRP)-conjugated respective secondary antibodies (Amersham Biosciences, Amersham, UK) and ECL solutions (Amersham Biosciences).

Immunohistochemical staining. Immunohistochemistry was used to detect the expression of PDCD4 protein in gastric cancer samples. The study population included 122 patients as described above. Immunohistochemical staining was performed on 4- $\mu \mathrm{m}$ sections obtained from formalin-fixed, paraffin-embedded blocks. Endogenous peroxidase activity was blocked with $3 \%$ hydrogen peroxide for $30 \mathrm{~min}$. Antigen retrieval was carried out in citrate buffer $(10 \mathrm{mM}, \mathrm{pH}$ 6.0) for $30 \mathrm{~min}$ at $95^{\circ} \mathrm{C}$. PDCD4 antibody (Cell Signaling Technology) at a dilution of 1:500 was applied and sections were incubated at $4^{\circ} \mathrm{C}$ overnight. Afterward, sections were incubated with a biotinylated secondary antibody and then exposed to a streptavidin complex (HRP). Positive reactions were visualized with 3,3'-diaminobenzidine tetrahydrochloride (DAB; Sigma-Aldrich), followed by counterstaining with hematoxylin. Normal tissue was used as a control. Sections treated without primary antibodies were used as negative controls. The percentage of positive-stained cells was graded semiquantitatively according to a four-tier scoring system: negative $(-), 0-5 \%$; weakly positive $(+), 6-25 \%$; moderately positive $(++)$, 26-50\% and strongly positive (+++), 51-100\%.

Cell cycle distribution and analysis of apoptosis. pT2a and pT2b gastric cancer samples and paired normal tissues were subjected to chemical digestion by incubation with $0.5 \%$
$\mathbf{A}$
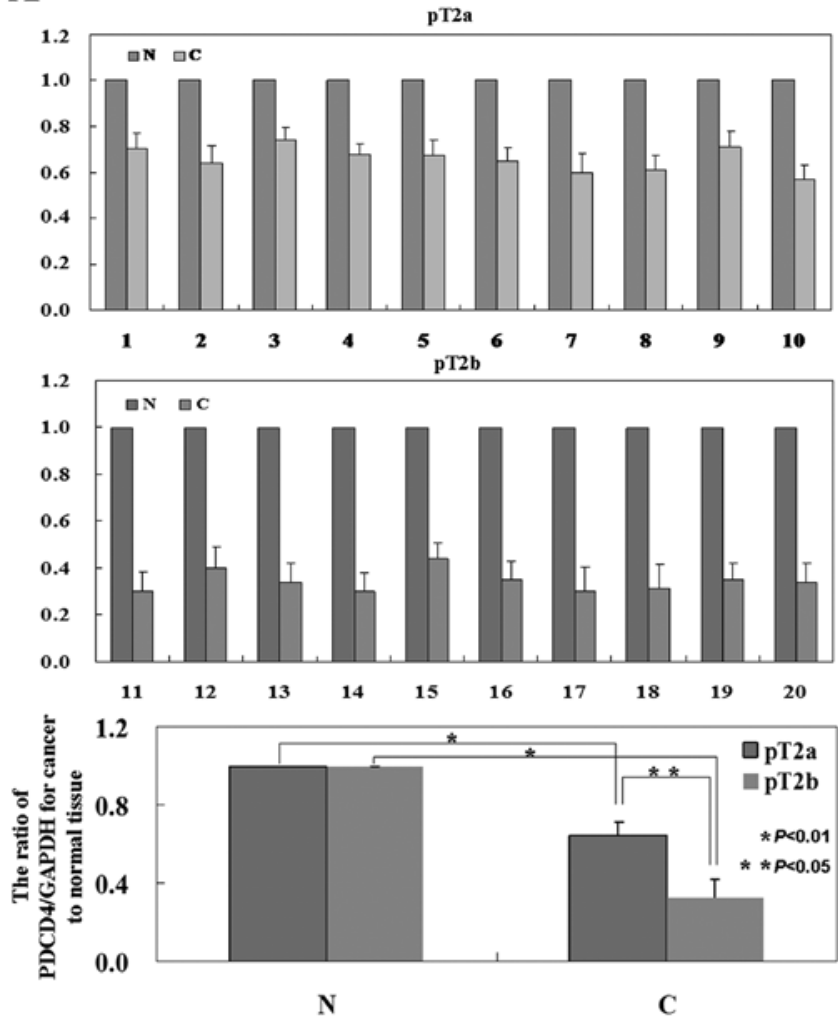

B
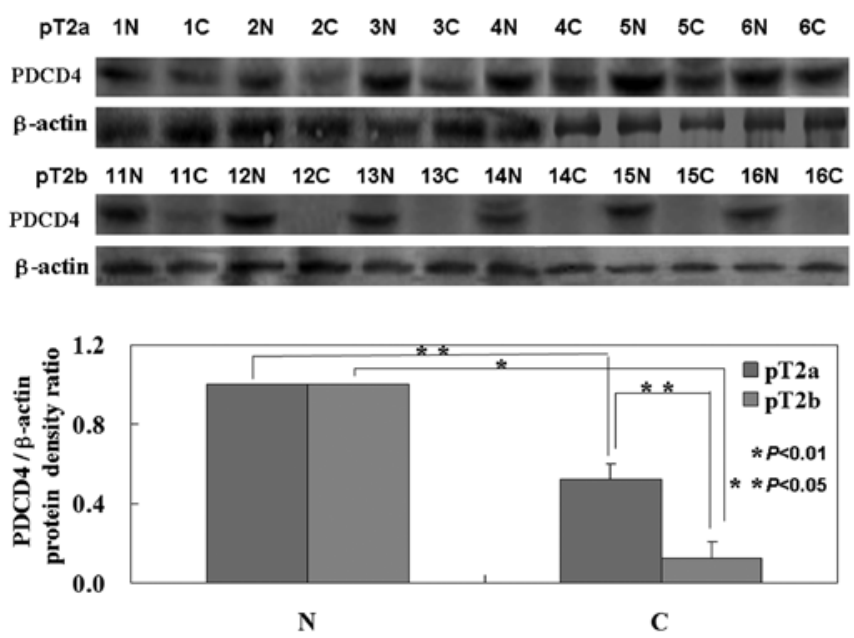

Figure 1. (A) The level of PDCD4 mRNA was measured in tissue specimens using real-time PCR. The level of PDCD4 mRNA was lower in cancer tissues compared with that in the matched normal tissues $(\mathrm{P}<0.05)$. GADPH was used as an internal control. (B) Representative results of two paired gastric cancer and corresponding normal tissues by western blot analysis with the anti-PDCD4 antibody. PDCD4 protein expression was lower in the gastric cancer tissues compared with that in matched normal tissues $(\mathrm{P}<0.05)$. $\beta$-actin was used as an internal control. $\mathrm{N}$, normal; $\mathrm{C}$, cancer.

pepsin (pH 1.5; Sigma-Aldrich) at $37^{\circ} \mathrm{C}$ in a water bath for 30 min with intermittent stirring. Disaggregated tissues were filtered through a 50- $\mu \mathrm{m}$ nylon mesh, washed twice with PBS and re-suspended in PBS. Cells were collected in PBS and fixed on ice with $1 \%$ paraformaldehyde, followed by $70 \%$ cold ethanol. After treatment with $10 \mu \mathrm{g} / \mathrm{ml}$ RNase, the cells were stained with $50 \mu \mathrm{g} / \mathrm{ml}$ propidium iodide (PI; KeyGen, Nanjing, 


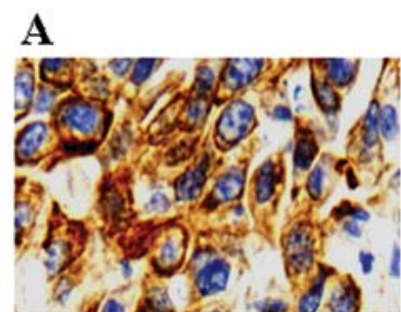

D

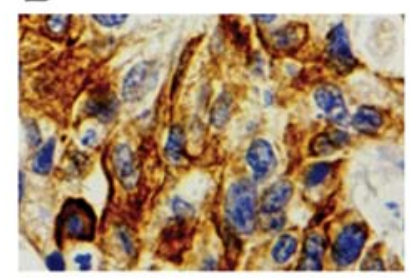

B

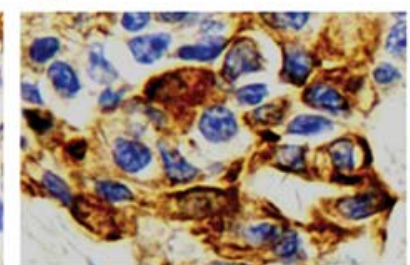

E

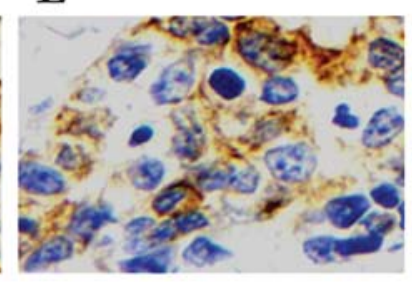

C

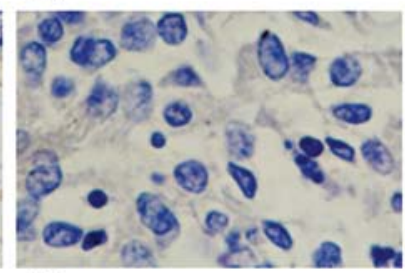

F

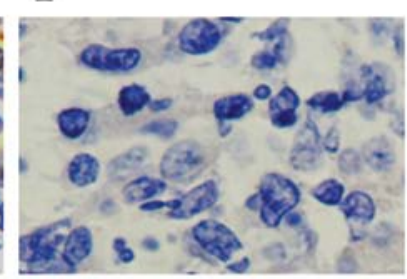

Figure 2. Immunohistochemical staining for PDCD4 protein in gastric cancer and matched normal tissue specimens. (A) pT2a stage gastric cancer, (B) paired normal tissues and (C) negative control. (D) pT2b stage gastric cancer, (E) paired normal tissues and (F) negative control. PDCD4 was stained yellow with granules and localized to the cytoplasm. The nuclei were counterstained with hematoxylin.

Table I. PDCD4 expression in the normal gastric tissues and pT2a and pT2b stage gastric cancer tissue.

\begin{tabular}{|c|c|c|c|c|c|c|c|c|}
\hline \multirow[b]{2}{*}{ Groups } & \multirow[b]{2}{*}{$\mathrm{n}$} & \multicolumn{4}{|c|}{ PDCD4 expression } & \multirow[b]{2}{*}{$\mathrm{PR}(\%)$} & \multirow[b]{2}{*}{$\chi^{2}$ value } & \multirow[b]{2}{*}{ P-value } \\
\hline & & - & + & ++ & +++ & & & \\
\hline Normal gastric tissue & 122 & 0 & 31 & 35 & 56 & 100.0 & 139.1 & 0.027 \\
\hline pT2a gastric cancer tissue & 60 & 39 & 10 & 6 & 5 & 35.0 & & \\
\hline pT2b gastric cancer tissue & 62 & 47 & 5 & 6 & 4 & 24.2 & & \\
\hline
\end{tabular}

PR, positive rate; $\chi^{2}$ value, Chi-square distribution.

China) for $15 \mathrm{~min}$ at room temperature for cell cycle analysis. The apoptotic cells were detected with Annexin V-FITC/PI double staining. The cells were trypsinized and stained with Annexin V-FITC and PI following the manufacturer's instructions for the Apoptosis Assay kit (KeyGen). The stained cells were analyzed by flow cytometry. Data analysis was performed with CellQuest software (BD Biosciences, Rockville, MD, USA).

Statistical analysis. All statistical analyses and graphics were performed using GraphPad Prism 5. Overall survival rates were determined using the Kaplan-Meier estimator. Kaplan-Meier survival plots were generated and comparisons were made with log-rank statistics. Cox's proportional hazard model was used to identify significant factors correlated with prognosis in multivariate analysis. For all analyses, $\mathrm{P}<0.05$ was considered to indicate a statistically significant result.

\section{Results}

Evaluation of the levels of PDCD4 $\mathrm{mRNA}$ and protein in pT2a and pT2b stage gastric cancer specimens. Real-time PCR was carried out to investigate the level of PDCD4 mRNA in gastric cancer specimens. The results indicated that the level of PDCD4 mRNA was lower in the gastric cancer specimens compared to that in the normal tissues $(\mathrm{P}<0.05$; Fig. $1 \mathrm{~A})$. To examine the relationship between the level of PDCD4 protein and the level of PDCD4 transcription, western blot analysis of the PDCD4 protein was carried out in gastric cancer specimens and the results showed that the level of PDCD4 protein was lower compared to that in the normal tissues and coincident with the level of mRNA ( $\mathrm{P}<0.05$; Fig. 1B). Notably, the levels of PDCD4 mRNA and protein were higher in pT2a stage cancer tissues compared with that in pT2b stage cancer tissues (Figs. 1 and 2).

PDCD4 expression is correlated with clinicopathological parameters of the patients with pT2 stage gastric cancer. The immunostaining results showed that PDCD4 expression was distributed in the cytoplasm of normal gastric and gastric cancer cells (Fig. 2). However, PDCD4 protein was weakly expressed in the gastric cancer tissues, while highly in the corresponding normal tissues. There was a significant difference in PDCD4 expression between the normal gastric tissues, when compared with that in the pT2a and pT2b stage gastric cancer tissues $(\mathrm{P}<0.05$; Table $\mathrm{I})$. We then analyzed the potential relationship between the expression of PDCD4 and the clinicopathological characteristics of these patients. The results are summarized in Table II. No correlation was found with patient gender, age, lymphatic invasion, venous 
Table II. Relationship between PDCD4 expression and clinicopathological parameters of the patients with pT2 stage gastric cancer.

\begin{tabular}{|c|c|c|c|c|c|c|c|c|}
\hline \multirow{2}{*}{$\begin{array}{l}\text { Clinicopathological } \\
\text { parameters }\end{array}$} & \multirow[b]{2}{*}{$\mathrm{n}$} & \multicolumn{4}{|c|}{ PDCD4 expression } & \multirow[b]{2}{*}{$\mathrm{PR}(\%)$} & \multirow[b]{2}{*}{$\chi^{2}$ value } & \multirow[b]{2}{*}{ P-value } \\
\hline & & - & + & ++ & +++ & & & \\
\hline Gender & & & & & & & 2.68 & 0.125 \\
\hline Female & 48 & 31 & 7 & 7 & 3 & 31.3 & & \\
\hline Male & 74 & 55 & 8 & 5 & 6 & 25.7 & & \\
\hline Age (years) & & & & & & & 4.78 & 0.227 \\
\hline$<65$ & 55 & 35 & 6 & 8 & 6 & 36.4 & & \\
\hline$\geq 65$ & 67 & 51 & 9 & 4 & 3 & 23.9 & & \\
\hline Tumor differentiation & & & & & & & 9.03 & 0.032 \\
\hline Differentiated & 53 & 30 & 10 & 8 & 5 & 43.4 & & \\
\hline Undifferentiated & 69 & 56 & 5 & 4 & 4 & 18.8 & & \\
\hline Lymphatic invasion & & & & & & & 0.53 & 0.148 \\
\hline - & 50 & 34 & 6 & 6 & 4 & 32.0 & & \\
\hline+ & 72 & 52 & 9 & 6 & 5 & 27.8 & & \\
\hline Venous invasion & & & & & & & 6.01 & 0.275 \\
\hline- & 68 & 48 & 9 & 9 & 2 & 29.4 & & \\
\hline+ & 54 & 38 & 6 & 3 & 7 & 29.6 & & \\
\hline Lymph node metastasis & & & & & & & 6.18 & 0.353 \\
\hline- & 42 & 27 & 8 & 2 & 5 & 35.7 & & \\
\hline+ & 80 & 59 & 7 & 10 & 4 & 26.3 & & \\
\hline Tumor size $(\mathrm{cm})$ & & & & & & & 10.57 & 0.041 \\
\hline$<4$ & 57 & 33 & 12 & 6 & 6 & 42.1 & & \\
\hline$\geq 4$ & 65 & 53 & 3 & 6 & 3 & 18.5 & & \\
\hline pN category & & & & & & & 4.47 & 0.079 \\
\hline pNO & 32 & 22 & 3 & 4 & 3 & 31.2 & & \\
\hline pN1 & 34 & 22 & 5 & 5 & 2 & 35.3 & & \\
\hline $\mathrm{pN} 2$ & 30 & 21 & 5 & 2 & 2 & 30.0 & & \\
\hline $\mathrm{pN} 3$ & 26 & 21 & 2 & 1 & 2 & 19.2 & & \\
\hline
\end{tabular}

PR, positive rate; $\chi^{2}$ value, Chi-squared distribution.

invasion, lymph node metastasis and $\mathrm{pN}$ category $(\mathrm{P}>0.05)$. However, PDCD4 expression was significantly associated with the level of tumor differentiation and tumor size $(\mathrm{P}<0.05)$.

Kaplan-Meier survival analysis and Cox's proportional hazard analysis. Follow-up information was available for 122 patients with gastric cancer for periods ranging from 3 months to 7 years (median, 42 months). Kaplan-Meier analysis showed that PDCD4 expression was closely correlated with a favorable prognosis of patients with pT2 stage gastric cancer $(\mathrm{P}<0.05$; Fig. $3 \mathrm{~A})$. Notably, the major clinical distinction between pT2a stage gastric cancer patients and pT2b stage gastric cancer patients was that PDCD4 expression showed no statistically significant effects on $\mathrm{pT} 2 \mathrm{~b}$ patient survival $(\mathrm{P}>0.05$; Fig. 3C) when compared with the pT2a patients $(\mathrm{P}<0.05$; Fig. 3B). Cox's proportional hazard analysis indicated that PDCD4 was an independent prognostic factor
Table III. Multivariate analysis of clinical variables for pT2a gastric cancer.

\begin{tabular}{lcc}
\hline $\begin{array}{l}\text { Clinicopathological } \\
\text { parameters }\end{array}$ & $\begin{array}{c}\text { Relative risk } \\
(95 \% \mathrm{CI})\end{array}$ & P-value \\
\hline Gender (male) & $1.98(1.27-3.24)$ & 0.305 \\
Age (>65 years) & $1.12(0.61-1.72)$ & 0.428 \\
Differentiation & $1.22(0.67-1.34)$ & 0.291 \\
Lymphatic invasion & $1.43(0.85-2.42)$ & 0.278 \\
Venous invasion & $0.51(0.21-1.52)$ & 0.456 \\
Lymph node metastasis & $0.78(0.34-1.75)$ & 0.334 \\
Tumor size ( $\geq 4$ cm) & $0.62(0.27-1.61)$ & 0.347 \\
PDCD4 expression & $5.94(1.53-12.34)$ & 0.015 \\
(+ to +++) & &
\end{tabular}

CI, confidence interval. 
A

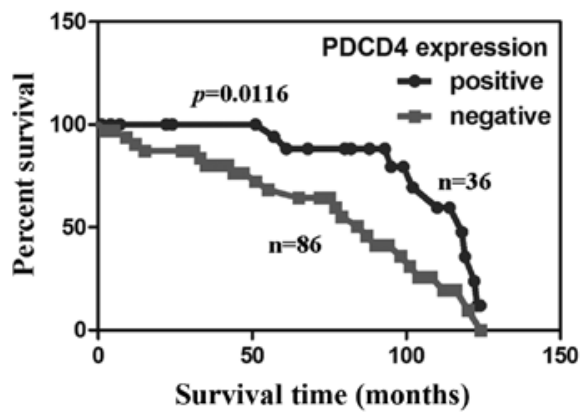

B

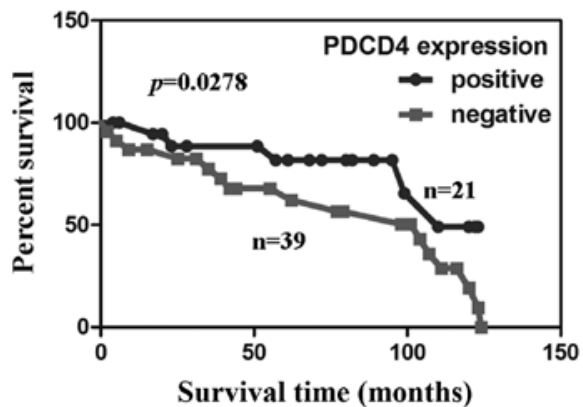

C

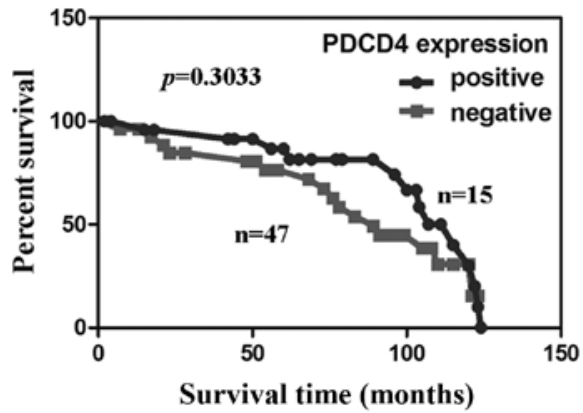

Figure 3. PDCD4 protein expression and prognosis of the patients with pT2 stage gastric cancer. Kaplan-Meier curves indicating the cumulative survival rate of patients with gastric cancer according to PDCD4 expression in the (A) overall, (B) pT2a stage and (C) pT2b stage gastric cancer patients.

Table IV. Multivariate analysis of clinical variables for $\mathrm{pT} 2 \mathrm{~b}$ stage gastric cancer.

\begin{tabular}{lcc}
\hline $\begin{array}{l}\text { Clinicopathological } \\
\text { parameters }\end{array}$ & $\begin{array}{c}\text { Relative risk } \\
(95 \% \mathrm{CI})\end{array}$ & P-value \\
\hline Gender (male) & $1.24(0.71-1.35)$ & 0.247 \\
Age $(>65$ years) & $1.17(0.56-1.22)$ & 0.291 \\
Differentiation & $1.09(0.43-1.12)$ & 0.357 \\
Lymphatic invasion & $1.56(0.93-2.58)$ & 0.294 \\
Venous invasion & $0.64(0.28-1.65)$ & 0.321 \\
Lymph node metastasis & $0.71(0.31-1.69)$ & 0.227 \\
Tumor size $(\geq 4$ cm) & $0.61(0.23-1.58)$ & 0.289 \\
PDCD4 expression & $4.86(1.33-9.34)$ & 0.028 \\
$(+$ to +++$)$ & &
\end{tabular}

CI, confidence interval.
$\mathbf{A}$
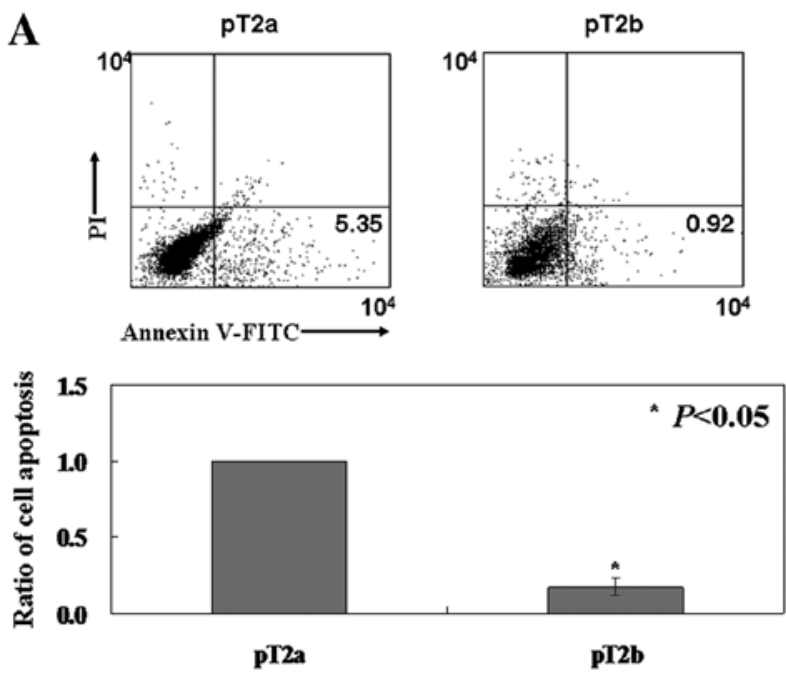

B
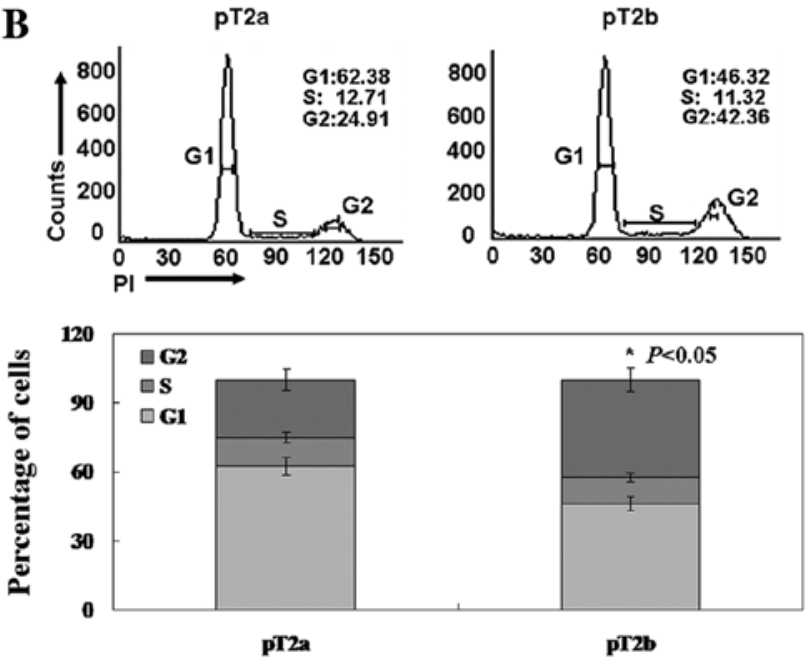

Figure 4. Assessment of pT2a and pT2b stage gastric cancer tissues by flow cytometry. (A) Apoptotic ratio of pT2 stage gastric cancer cells was determined using Annexin V/PI double-staining assays. The histogram indicates statistically significant results $(\mathrm{P}<0.05)$. (B) Propidium iodide $(\mathrm{PI})$ staining showed changes in the cell cycle distribution. The histogram shows that the results have statistical significance $\left({ }^{*} \mathrm{P}<0.05\right)$. for $\mathrm{pT} 2 \mathrm{a}$ and $\mathrm{pT} 2 \mathrm{~b}$ stage gastric cancer $(\mathrm{P}<0.05$; Tables III and IV).

Assessment of cell cycle distribution and apoptosis by flow cytometry. We compared the cell cycle distribution and percentage of apoptotic cells obtained from pT2a and pT2b gastric cancer tissue by flow cytometry. The percentage of apoptotic cells present was determined using flow cytometry to detect cells positively stained with Annexin V-FITC and propidium iodide (PI). As shown in Fig. 4A, the percentage of apoptotic pT2a cells was $5.35 \pm 0.34 \%$, whereas $0.92 \pm 0.12 \%$ of pT $2 \mathrm{~b}$ cells were undergoing apoptosis $(\mathrm{P}<0.05)$. A higher percentage of cells from $\mathrm{pT} 2 \mathrm{~b}$ stage gastric cancer tissue was noted in the $\mathrm{G}_{2}$ phase of the cell cycle when compared with the percentage of cells from the pT2a gastric cancer tissue. The mean percentage of the $\mathrm{G}_{2}$ phase fraction of pT2a and pT2b stage gastric cancer cells was $24.9 \pm 3.4$ and $42.3 \pm 4.8 \%$, respectively ( $\mathrm{P}<0.05$; Fig. 4B). 


\section{Discussion}

In the present study, levels of PDCD4 mRNA and protein expression were assessed in a total of 122 gastric cancer tissue specimens. We demonstrated a decreasing trend for both mRNA and protein expression of PDCD4 in pT2a and pT2b stage gastric cancer tissues. Motoyama et al (17) demonstrated through a panel of primary specimens and cell culture models that PDCD4 $\mathrm{mRNA}$ /protein expression is lower in gastric cancer tissues compared to corresponding normal tissues. This indicates that PDCD4 may play a role in human gastric carcinogenesis. Notably, we also found that the levels of mRNA and protein expression of PDCD4 were higher in pT2a gastric cancer tissues than that in pT2b gastric cancer tissues. Consistent with a previous study, reduced expression of PDCD4 is related to advanced tumor stage in gastric cancer (17). Loss of PDCD4 in lung cancer was correlated with higher histological grade, disease stage and poor prognosis (14). In our study, loss of PDCD4 expression was significantly associated with differentiation and tumor size of both pT2a and pT2b stage gastric cancer tissues. Previous studies have demonstrated that PDCD4 is an independent risk factor in lung (14) and colon cancer $(15,18)$. However, to the best of our knowledge, no similar studies have been carried out in gastric cancer. We initially found that PDCD4 was an independent risk factor in pT2 stage gastric cancer. Furthermore, we confirmed that reduced PDCD4 expression was significantly associated with low overall survival rate. There is no doubt that reduced PDCD4 is a negative prognostic factor in primary lung cancer (14), colon cancer (15), ovarian cancer (19) and glioma (20). However, we found that reduced PDCD4 did not affect the survival of pT2b stage gastric cancer patients. The reason may be that the level of PDCD4 protein in pT2b stage gastric cancer patients is too low to exert a function.

PDCD4 has been reported as an inducer of apoptosis $(21,22)$. In our study, we confirmed that cells obtained from pT2a tumor specimens had a higher apoptotic ratio than cells from pT2b tumor tissue specimens. This indicates that PDCD4 induces apoptosis in gastric cancer cells. In addition, we also found that PDCD4 inhibits the cell cycle. Cells obtained from pT2a tumor tissue specimens consisted of a small percentage of cells in the $G_{2}$ phase when compared to cells from pT $2 b$ tumor tissue specimens. To our knowledge, this is the first report concerning the relationship between PDCD4 and the cell cycle in gastric cancer.

Taken together, we demonstrated that PDCD4 is associated with pT2 stage gastric cancer. The results are not only of relevance for diagnosis and prognosis, but may also provide a novel target for $\mathrm{pT} 2 \mathrm{a}$ and $\mathrm{pT} 2 \mathrm{~b}$ stage gastric cancer therapies.

\section{Acknowledgements}

We are indebted to Wang Ning and Li Sun for their help with the statistical analysis.

\section{References}

1. Jemal A, Bray F, Center MM, et al: Global cancer statistics. CA Cancer J Clin 61: 9-90, 2011.

2. Sarela AI, Turnbull AD, Coit DG, et al: Accurate lymph node staging is of greater prognostic importance than subclassification of the T2 category for gastric adenocarcinoma. Ann Surg Oncol 10: 783-791, 2003.

3. Kunisaki C, Shimada H, Nomura M, et al: Distribution of lymph node metastasis in gastric carcinoma. Hepatogastroenterology 53: 468-472, 2006.

4. Potrc S, Gadiijev E, Hajdinjak T, et al: Clinicopathological and immunohistochemical markers after radical gastrectomy for gastric cancer. Hepatogastroenterology 54: 308-314, 2007.

5. Greene FL, Page DL, Fleming ID, et al (eds): AJCC Cancer Staging Manual. 6th edition. Springer-Verlag, New York, 2002.

6. Ebert MP, Fei G, Kahmann S, et al: Increased beta-catenin mRNA levels and mutational alterations of the APC and beta-catenin gene are present in intestinal-type gastric cancer. Carcinogenesis 23: 87-91, 2002.

7. El-Rifai W and Powell SM: Molecular biology of gastric cancer. Semin Radiat Oncol 12: 128-140, 2002

8. Cmarik JL, Min H, Hegamyer G, et al: Differentially expressed protein Pdcd4 inhibits tumor promoter-induced neoplastic transformation. Proc Natl Acad Sci USA 96: 14037-14042, 1999.

9. Soejima H, Miyoshi O, Yoshinaga H, et al: Assignment of the programmed cell death 4 gene (PDCD4) to human chromosome band 10q24 by in situ hybridization. Cytogenet Cell Genet 87: 113-114, 1999.

10. Afonja O, Juste D, Das S, et al: Induction of PDCD4 tumour suppressor gene expression by RAR agonists, antiestrogen and HER-2/neu antagonist in breast cancer cells. Evidence for a role in apoptosis. Oncogene 23: 8135-8145, 2004.

11. Bitomsky N, Wethkamp N, Marikkannu R, et al: siRNA-mediated knockdown of PDCD4 expression causes upregulation of p21 (Waf1/Cip1) expression. Oncogene 27: 4820-4829, 2008.

12. Carayol N, Katsoulidis E, Sassano A, et al: Suppression of programmed cell death 4 (PDCD4) protein expression by BCR-ABL-regulated engagement of the mTOR/p70 S6 kinase pathway. J Biol Chem 283: 8601-8610, 2008.

13. Yoshinaga H, Matsuhashi S, Fujiyama C, et al: Novel human PDCD4 (H731) gene expressed in proliferative cells is expressed in the small duct epithelial cells of the breast as revealed by an anti-H731 antibody. Pathol Int 49: 1067-1077, 1999.

14. Chen Y, Knosel T, Kristiansen G, et al: Loss of PDCD4 expression in human lung cancer correlates with tumour progression and prognosis. J Pathol 200: 640-646, 2003.

15. Mudduluru G, Medved F, Grobholz R, et al: Loss of programmed cell death 4 expression marks adenoma-carcinoma transition, correlates inversely with phosphorylated protein kinase $\mathrm{B}$, and is an independent prognostic factor in resected colorectal cancer. Cancer 110: 1697-1707, 2007.

16. Zhang H, Ozaki I, Mizuta T, et al: Involvement of programmed cell death 4 in transforming growth factor-betal-induced apoptosis in human hepatocellular carcinoma. Oncogene 25: 6101-6112, 2006.

17. Motoyama $\mathrm{K}$, Inoue $\mathrm{H}$, Mimori $\mathrm{K}$, et al: Clinicopathological and prognostic significance of PDCD4 and microRNA-21 in human gastric cancer. Int J Oncol 36: 1089-1095, 2010.

18. Asangani IA, Rasheed SA, Nikolova DA, et al: MicroRNA-21 (miR-21) post-transcriptionally downregulates tumor suppressor Pdcd 4 and stimulates invasion, intravasation and metastasis in colorectal cancer. Oncogene 27: 2128-2136, 2008.

19. Wang X, Wei Z, Gao F, et al: Expression and prognostic significance of PDCD4 in human epithelial ovarian carcinoma. Anticancer Res 28: 2991-2996, 2008.

20. Gao F, Wang X, Zhu F, et al: PDCD4 gene silencing in gliomas is associated with $5^{\prime} \mathrm{CpG}$ island methylation and unfavourable prognosis. J Cell Mol Med 13: 4257-4267, 2009.

21. Shibahara K, Asano M, Ishida Y, et al: Isolation of a novel mouse gene MA-3 that is induced upon programmed cell death. Gene 166: 297-301, 1995.

22. Zhang Z and DuBois RN: Detection of differentially expressed genes in human colon carcinoma cells treated with a selective COX-2 inhibitor. Oncogene 20: 4450-4456, 2001. 